Peer-Reviewed Article

ISSN: 2162-3104 Print/ ISSN: 2166-3750 Online

Volume 6, Issue 2 (2016), pp. 588-613

(C) Journal of International Students

http://jistudents.org/

\title{
Leaving Home: The Challenges of Black-African International Students Prior to Studying Overseas
}

\author{
Elizabeth Frances Caldwell \\ University of Huddersfield (UK) \\ Denis Hyams-Ssekasi \\ University of Bolton (UK)
}

\begin{abstract}
Much of the literature on international students centres on their experiences once they arrive in their host countries. This study explores the preparations of Black-African students for leaving their home countries to study abroad. Semi-structured interviews were carried out with 50 Black-African students studying at one British university. The students spoke of the complex and frustrating process of obtaining visas and applying to university abroad as well as the tensions they felt in leaving their communities. These pressures were extensive and impacted their subsequent ability to adjust to life in their host institution. A greater understanding of the backgrounds of international students will enable higher education professionals to develop more culturally inclusive universities.
\end{abstract}

Keywords: Black-African students; international students; adjustment; transition; inclusive education

In recent years, it has been noticed that academic performance and employment outcomes differ between different groups of students. 
For example, in the UK, disabled students have an overall better academic performance than non-disabled students, but Black, minority and ethnic (BME) students perform less well than White students (BIS, 2014). As Cotton, George and Joyner (2010) point out, these differences are not attributed to study time or attendance but instead are related to adapting to the culture in Higher Education Institutions (HEIs). The notion of inclusivity in education aims to promote fairness and equity in HEIs by "taking account of and valuing students' differences within mainstream curriculum, pedagogy and assessment" (Hockings, 2010, p.3). Much of the discussion on inclusivity and student differences stems from the changes in the make-up of the student body resulting from expansion of higher education (HE), which does "not simply bring more students into HE but, rather, attracts different types of students" (Cottrell 2001, p.5). Discussions of this diversity on campus often list a variety of characteristics or groups of students that should be considered, such as mature, disabled, students from different social classes and cultural backgrounds, different sexual orientations and different faiths (see for e.g. Hockings, 2010). However, such lists rarely include international students, and if they appear at all, they are almost always grouped together as one entity. Whilst higher education professionals have become used to dissecting the diverse needs of the domestic student body, it seems the implications of the diversity found among international students studying in the West are less often considered.

The most cursory of examinations reveals that international (i.e. non-domiciled) students are far from a homogenous group (HESA, 2015). And yet in both the academic literature, and in institutional structures, international students are commonly discussed as single entity (Hyland, Trahar, Anderson \& Dickens, 2008). However, as Andrade (2006) points out, combining all international students in this way masks the important challenges faced by particular groups during their time at the host university. Not only do international students come from a vast range of countries and cultures, they also come from different backgrounds within those societies (Manyika, 2001). African students are the third largest group of international students in the UK (HESA 2014), and evidence is emerging that they are subject to a number of specific challenges as they enter and acclimatize to academic life in the West. There are to 
date only a small number of studies of the experiences of African students studying in the UK, but a number of studies from the USA report that Black-African students studying there face greater amounts of prejudice and discrimination than other groups of international students (Boafo-Arthur 2014; Hanassab, 2006; Lee and Opio, 2011). In addition, issues with English language proficiency are often cited as the greatest source of concern to East Asian students, but both Blake, (2006) and Hyams-Ssekasi, Mushibwe and Caldwell (2014) found that this was less of a concern for BlackAfrican students, many of whom have had previous experience of being taught in English. Mwara (2008) and Hyams-Ssekasi et al. (2014) also found that just as for domestic students, older international students have more adjustment problems than younger, "traditional" age, students.

As Sidoryn and Slade (2009, p.1) point out, "the place students are coming from affects their experiences at university in relation to the social and academic environment, as they come from the familiar to the unfamiliar". Interestingly, there is little research on the lives of international students before they arrive at their destination institutions, as the majority of research centers around problems with language, or adjustment issues once the students have arrived in their host country. This lack of awareness about the backgrounds of our international students has contributed to the phenomenon of them being treated as a homogenous group and has also led to a number of erroneous assumptions. Examples of these beliefs include the notion that international students lack Englishlanguage ability (see Hanassab, 2006), and that they come from wealthy families (Fischer, 2011). The aim of this paper is to shed light on the backgrounds of a group of Black-African students so that we may better understand where they are coming from and ultimately to enable us to design more culturally inclusive learning experiences.

\section{LITERATURE REVIEW}

\section{Separation and transition}

The process of settling in and adapting to life in a new country and institution is often described as a transition whereby one 'unplugs' from the old world and 'plugs' into the new; a process that 
starts with an ending and finishes with a beginning (Bridges, 2003). Bridges argues that transition is about the experience individuals have in the here and now and not what they are seeking tomorrow. He further postulates that transition should not be perceived as a passive phase but as an active and interactive process in which the transitioning individuals play a greater role in the process by accepting their responsibility and the challenges. Schlossberg, Waters and Goodman (1995, p.27) describe the transition as being characterized by a "moving out" stage, followed by "moving in" to the new situation and absorbing the norms and rules of the new place, until the individual can successfully "move through", or navigate and survive in, the new world. Nortier (1995) asserts that "our experience has taught us that transition, whatever it may be, is a process internal to the individual, slow and progressive, not demarcated in time" (p.38). There are 'normal' transitions which an individual must go through that are anticipated, expected and occasionally planned and therefore these can be handled with minimum disruption (Lewthwaite, 1996; Schlossberg, 1984). On the other hand there are larger transitions which are either unexpected or unplanned and occasionally unwanted (te Riele, 2004; Zhoua, 2008). Such transitions happen outside the bounds of everyday living and involve the individual learning a wide range of new behaviors and cultural practices (Hyams-Ssekasi, 2012).

Bridges (2003) suggests that it is the ending of the old situation and identity that occurs before the move which can be the largest difficulty that people face in any transition. According to Van Gennep (1960), this ending phase, which he called, 'separation' involves the individual dissociating themselves from their previous communities, families and friends and the old self being erased in preparation for the new one. Tinto (1987) asserts that separation can be perceived as a temporal rejection of families and deeply rooted values leading to adaptation of new values and situations that are dissimilar to the previous experiences. Lee and Opio (2011) claim that Black-African international students have greater problems incorporating into their new university environment than separating from their home. However, Tito (1987, p. 97) states that: "foreign students, students from very small rural communities, and students 
from distinct social, ethnic or religious communities may also find separation particularly difficult."

Schlossberg et al. (1995) point out that separation can be a painful process and involve feelings of grief as the old identity is lost. Maunder, Cunliffe, Galvin, Mjali and Rogers ( 2013) argue that there is a relationship between the transition to being a university student and identity change and it is clear that for many Black-African international students the struggle to find a new identity as an 'international student', 'Black', and 'foreigner' can be disorientating (Hyams-Ssekasi, 2012; Lee \& Opio, 2011; Lee \& Rice, 2007). In Beoku-Betts', (2006) study of female African graduate students, one respondent comments: "I lost my identity. I became the Black girl. A lot of them assumed I couldn't understand English or [that I was dumb]." (p.146). A number of studies have found that Black-African students are reluctant to relinquish their former identities and embrace their new position in the host country's society, due to the cultural marginalization by their former colonizers (Beoku-Betts 2006; Lee and Opio, 2011, Maringe and Carter 2007). As one student in Hyams-Ssekasi et al. 's (2014, p.8) study explains: "If you are not careful you can lose your confidence and self-esteem in this country. The values we have in Africa are looked down on. Talk about our traditions, they are still considered backwards, only good enough for research." Whilst there are clearly emotional and psychological issues to deal with in leaving families and communities, there are also a number of practical issues to overcome before the start of the journey. The next section will outline a number of specific challenges that apply to students considering applying to university abroad.

\section{The challenges of applying to university abroad}

The complex process of applying to university abroad and obtaining a visa occupies much of the attention of prospective international students (Serra Hagedorn and Yi Zhang, 2011). These include completing and financing visa applications, visa interview(s) or counselling as well as coping with the anxiety of being refused a visa (Butcher, 2002). Common reasons for visas being turned down include: not supplying original documents, not being able to demonstrate sufficient funds and using counterfeit documents (Lipset, 2009). Sidy (2007) claims that African students are more likely to be 
denied a visa than those from other developing countries due to a concern that they might intend to migrate permanently and that they may not be able to fully fund their studies. Maringe and Carter (2007) point out that recruiters often find it difficult to establish whether a student has the means to pay their fees and it has not gone unnoticed by those working with international students that some students "borrow money to fulfil visa purposes and then have to give it back" (National Union of Students, 2014, p.24). For those students who undertake this course of action, it can add enormous pressure to earn money both whilst studying and after they graduate (HyamsSsekasi et al., 2014).

As many authors have pointed out, the transition to university, and studying abroad, is eased with adequate preparation (Fischer, 2011; Yorke, 1999). Several studies have found that migrants who did not adequately prepare, or had unrealistic expectations, were more likely to suffer from depression (Chou, 2009; Ryan, Leavey, Golden, Blizard and King 2006). When moving to a distant country, students are often reliant on very limited sources of information to help them prepare for the transition. Interestingly, Maringe and Carter (2007) reported that the Black-African students in their study were disappointed with the information they received from their university prior to arrival, particularly about the likelihood of being to earn money whilst studying in the UK. This is a particular issue for many self-funded Black-African students, who have often borrowed money from family and friends to pay for their studies (Hyams-Ssekasi, et al., 2014). Whilst it is possible for students to work in the UK under current visa arrangements, the only jobs available to most students are poorly paid, meaning that students must work long hours in lowskilled jobs to make ends meet. It seems that there are tensions between the desire for Western universities to market themselves in a positive light, and the realities of life for certain international students. In a report by the National Union of Students (NUS) (2014) one student hardship fund manager commented:

I battled with my marketing team as I wanted to put that any part time work they found would probably be minimum wage and low grade and marketing said it was "too negative." However, this is because this is a reality and we were seeing 
teachers and engineers etc coming to the UK and thinking they would find jobs in those areas to support their studies and of course this is rare to find that level of part time work whilst studying. (p. 24)

The information that is available to prospective international students is often provided through educational agents, who are often used by HEIs in new and unstable markets, in order to lessen the costs and risks of expansion into these areas (Hulme, Thomson, Hulme \& Doughty, 2014). The agents act as a "one-stop-shop" (Pimpa, 2003, p. 180) and "a face to talk to" (Hulme et al., 2014, p.684) for prospective international students and they provide a range of services such as providing an initial point of contact for HEIs, advice on courses on offer, as well as support with applications, English proficiency requirements and visas (Pimpa, 2003; Hulme et al., 2014). However, a number of authors have reported issues with the ethical practices of these agents, including corruption, forgery, misrepresentation, and making false promises (Altbach, 2012; Hulme et al., 2014; Huang, Raimo \& Humfrey, 2014; Lewin, 2008; Serra Hagedorn and Yi Xhang 2011; Sharma 1997). In Hulme et al.'s (2014) study, one International Officer described the majority of agents as being "one level from being outright crooks" (p.682).

The hurdles that international students have to overcome before they even arrive in a host country are rarely discussed or acknowledged by educators. Far from recognizing the resourcefulness and determination of the students for navigating the complex and uncertain administrative processes, we assume that the international student experience starts on arrival to their chosen host country. To counter this, our study aims to shed light on the experiences of students as they prepare to leave their country. These stories can then provide the context for understanding the adjustment issues that this particular group of students may face.

\section{RESEARCH METHOD}

This study was conducted using an interpretive approach involving a qualitative exploratory research design (Bryman, 2004). The study used grounded theory to inform the research design, research questions, sampling and analysis (Harry, Sturges, and Klingner, 
2005). Ethics approval was granted by the ethics committee at the institution and measures were taken to ensure confidentiality and protect the anonymity of participants. Initially African international students in their first year of undergraduate study in one department in the university were approached by email. Participants were interviewed for between 45 and 60 minutes, and the semi-structured interviews were audio-recorded and later transcribed. Additional participants from the rest of the university were then recruited via snowballing (Bryman, 2004), giving a total sample of 50 participants (see Table 1). A thematic analysis of the interview transcripts was carried out. This involved manually coding the transcripts to identify the emergence of recurrent themes, words and concepts that were relevant to the research objectives (see Braun and Clarke, 2006).

The study used both insider and outsider investigators. As in Lee and Opio's (2011) study, the first author was an outsider to the African international student community, but has both taught and carried out research with international students in the UK. The interviews were conducted by the second author of this study, the 'insider', who in this case was a mature, African research student. Although, as Burton, Brundrett and Jones (2008) caution, insider research can raise issues to do with the balance of power, ownership and anonymity, it can also aid in building trusting relationships and rapport with participants (McNeil and Chapman, 2005). In this case, the 'insider' was not only culturally closer to the participants, but was also directly familiar with the issues concerning African students. Hyams-Ssekasi et al. (2014) found that African students often feel as though White British culture is alien to them and that their needs and circumstances are often misunderstood by university staff and services.

We acknowledge that our analysis considers the citizens of 12 different countries together as one group of 'African' students. However, as Beoku-Betts (2006) points out, individuals from African countries do often associate themselves with the term African when abroad (see also Hyams-Ssekasi et al. 2014), and with the exception of a relatively low number of students from Zimbabwe, the sample did broadly reflect the relative composition of African nations represented in the institution under study. It would, of course, be interesting to do further studies to elucidate the differences in 
community attitudes to studying abroad between the various African cultures. Though, given the number of different cultures in the continent and the modest numbers of African students studying in the West, to gain a suitable sample size for a range of inter-cultural comparative analyses would be logistically challenging.

\section{RESULTS}

\section{Background of participants}

A total of 50 African international students from one UK university participated in the research (see Table 1). The sample contained slightly more female participants (28) than male (22), however in the analysis we did not detect substantial differences between the narratives of men and women. The majority of the participants $(86 \%)$ were 'mature students' (i.e. over 21 years old) and all but two of the participants were undergraduate students. Interestingly, 86\% came from rural and relatively under-developed areas whereas $14 \%$ came from cities. As one student in our study described: "There are no proper houses in my village. Most of the houses are made out of mud and reeds and thatched roof houses or huts with no electricity" [Student 48, Zimbabwe].

We should point out here that by providing this background information on the participants, we are not trying to re-enforce negative stereotypes of Africa as 'backward' (see Beoku Betts 2006; Lee and Opio, 2011), but that we are challenging the common assumption that international students are rich and come from the most developed parts of their countries. One student in HyamsSsekasi et al.'s (2014, p.6) study explains about university administrators: "For them, an international student is a rich person from a poor developing country because he/she is in the UK." One thing that is clear is that the data in both Hyams-Ssekasi et al.'s (2014) study and that reported here show a departure from the state of affairs in colonial times, when African students that studied in Europe came from the elite or nobility (Leney, 1999). As another of our participants explained:

Before I came to the UK, I thought my parents were rich, but ... I could not believe when one of the English students told me that he had his own car parked outside the halls of 
residence. In my country, possessing a car and living in a corrugated iron house are considered to be signs of richness. [Student 9, Gambia]

\section{Table 1: Demographics of research participants}

\begin{tabular}{|c|c|c|c|c|c|c|c|c|c|}
\hline \multirow{2}{*}{$\begin{array}{l}\text { Country of } \\
\text { Origin }\end{array}$} & \multicolumn{2}{|c|}{$\underline{\text { Gender }}$} & \multicolumn{2}{|c|}{ Degree } & \multicolumn{2}{|c|}{ Home location } & \multicolumn{2}{|l|}{$\underline{\text { Age }}$} & \multirow[t]{2}{*}{ TOTAL } \\
\hline & $\mathrm{M}$ & $\mathrm{F}$ & UG & $\mathrm{PG}$ & Urban & Rural & $<21$ & $>21$ & \\
\hline Angola & & 1 & 1 & & & 1 & 1 & & 1 \\
\hline Cameroon & 1 & & 1 & & & 1 & & 1 & 1 \\
\hline Congo & 1 & 1 & 2 & & & 2 & & 2 & 2 \\
\hline Gambia & 3 & 1 & 4 & & & 4 & & 4 & 4 \\
\hline Ghana & 3 & 3 & 6 & & 1 & 5 & & 6 & 6 \\
\hline Kenya & & 2 & 1 & 1 & 1 & 1 & & 2 & 2 \\
\hline Nigeria & 6 & 7 & 12 & 1 & 2 & 11 & 1 & 12 & 13 \\
\hline South & 1 & 1 & 2 & & & 2 & & 2 & 2 \\
\hline Africa & & & & & & & & & \\
\hline Sudan & 1 & 3 & 4 & & & 4 & 1 & 3 & 4 \\
\hline Uganda & & 1 & 1 & & & 1 & 1 & & 1 \\
\hline Zambia & 1 & 5 & 6 & & 1 & 5 & & 6 & 6 \\
\hline Zimbabwe & 5 & 3 & 8 & & 2 & 6 & 3 & 5 & 8 \\
\hline TOTAL & 22 & 28 & 48 & 2 & 7 & 43 & 7 & 43 & 50 \\
\hline
\end{tabular}

Note: $\mathrm{M}=$ Male, $\mathrm{F}=$ Female, $\mathrm{UG}=$ Under Graduate, $\mathrm{PG}=$ Post Graduate

All but four of our participants came from countries that were former British colonies and so had extensive previous experience of studying in an English medium environment. This reflects the fact that only $5.1 \%$ of African international students studying in the UK are from countries that do not have this colonial link (HESA, 2010). According to Maringe and Carter (2007) students tend to migrate to their former colonial masters because of their shared language and culture. One student in our study commented: "Most people from my country come here because the country was colonized by the British. It is only country we have learnt about" [Student 43 Zimbabwe].

The students in our study mentioned choosing the UK for a variety of reasons, but a recurrent theme was the colonial background and the fact that English is a lingua franca in their country. This concurs with Blake (2006) and Hyams-Ssekasi et al. (2014) who both 
found that African international students do not report significant problems with English language whilst studying abroad. This is in contrast to other groups of international students, who often cite a lack of proficiency in English as the major barrier to adjustment to life in Western universities (Abdullah, Ismail, Aziz, Latiff, \& Ibrahim, 2014).

\section{Preparations for leaving}

Two main topics emerged from the data on the students' preparations to leave their country to study abroad. These were practical challenges in completing the application process and the social considerations for leaving their communities.

The challenges of the application process. It was clear that for most students obtaining the necessary student visa was a complicated, arduous and stressful process. The students spoke of having to be "lucky" and that visas are "not guaranteed" and "very difficult to get". Interestingly, Serra Hagedorn and Yi Xhang (2011) also report significant anxiety amongst Chinese students about whether they will be granted their visa, even though applications from Chinese students are often successful. The students in our study also talk of their "confusion" as well as a lack of necessary information from the university. Over two thirds of our participants had their visa applications denied before eventually being successful. One student also talks of being denied a visa because the Embassy official "concluded that I did not have the right intention to come to study" [Student 7, Gambia]. Lipset (2009) points out that there is a general perception, that international students are "treated with great suspicion by most British authorities" (p.1). Moreover, students from rural Africa face additional challenges:

The first time I was called for the interview at the British Embassy, I dreaded it because I had not travelled far away from my village. I was totally confused... We had to wake up very early morning, 3:00am to be precise, to board a bus. In the middle of nowhere the bus broke. We had no other option except to jump in the back of a pickup truck. The journey, less than 150 miles, took more than 8 hours. When we arrived at 
the Embassy, I was told to go away, complete the correct form and to bring more financial proof. [Student 4 , Zambia]

Not only is travel to the embassy long, frustrating and expensive, students often have problems with producing the necessary documentation to verify their identity. Births and marriages that occur in rural areas are often undocumented and in some communities residents may not even have a home address (Unicef, 2003). A Gambian student explains: "I have never had a birth certificate. I had one done when I was making my application forms. I did not even have a marriage certificate because I married in the village" [Student, 10, Gambia]. A similar situation often arises when asked to provide evidence of financial status as many adults do not hold bank accounts: "My parents did not have a bank account. They used my uncle's account to show evidence to the British Embassy and to pay for the tuition fees" [Student 29, Nigeria]. This lack of documentation may seem unusual to some in the West, where birth registration is mandatory, and bank accounts are "nearly ubiquitous" (Weise, 2012). However, according to Unicef (2003) in sub-Saharan Africa, 70\% of births went unregistered in 2000, and only $27 \%$ of adult men and $22 \%$ of adult women in Africa hold bank accounts (Economist, 2012).

Due the their prior experience of English medium education, gaining the required standard in the required English proficiency test was not a major concern for the students in our study, it was merely another document that had to be paid for:

I sat for the test at the British Council in my country because the university wanted me to have at least a grade 5.5 score...The British embassy had included it as one document I should show. It is expensive and I had to look for money again which was annoying because I had a merit at GCSE in English so what was the point. [Student 3, Zambia]

This contrasts with the Chinese students in Serra Hagedorn and Yi Xhang's (2011) study, who considered gaining English language qualifications to be the most challenging and time consuming part of their application. 
To university staff in the UK, for whom birth certificates and bank accounts are the norm, the process of applying for university place and a student visa might be assumed to be a mild inconvenience at the start of the journey. However, it is clear from the students in our study that this crucial step is fraught with difficulties and uncertainty as well as being time consuming and expensive. It is thus not surprising that students often turn to agents to assist in the application process. As mentioned in the literature review, a number of concerns have been raised about the ethical integrity of some educational agents. The students in our study were not specifically asked about whether they used an agent, but were asked about the obstacles they experienced prior to coming to study in the UK. In this context, many of the students did tell us about their experiences of using agents, as well as the reputation that the agents have: "Corruption ... is rife at the agents ... where a number of local people have been employed as staff. The local staff may demand a sum of money indicating they will help push the documents through or guarantee approval" [Student 45, Zimbabwe]. This is borne out by the fact that two of our Nigerian students told us that they had been asked by agents to pay "additional fees" to speed up the application process. This unethical practice clearly has an impact on the students: "...when I asked her whether my application form was already processed or not, she asked me to give her more money. I felt upset, angry, cheated but could not do anything to this agent" [Student 33, Nigeria].

Interestingly, the 11 African student respondents to the questionnaire in Hulme et al.'s (2014) study did not report any negative experiences in using agents and described their services as of "great value" (p.685). However, academic staff in Huang et al.'s (2014) raised concerns about the quality of the service they provide to students. In our study, students felt "naïve" about the role of the agent and their relationship to, and influence on, the embassy and university. They also did not always realize that agents can often work for more than one university. As one International Officer in Hulme et al.'s (2014) study claims, agents "shroud this visa in mystery to make applicants use their services" (p.682). Huang et al. (2014) suggest that one of the problems of using agents is that they make false promises to students about life in the UK. This poignant 
quote from one of our students illustrates the predicament that students can find them in, based on trusting the words of unscrupulous agents: "I do not know how I am going to pay back the money I got from friends to come here... The agents back home assured me that jobs are available for students. Is it true?" [Student 35, Nigeria]. Both Hyams-Ssekasi et al. (2014) and Maringe and Carter (2007) found that the greatest source of anxiety for BlackAfrican students was finances and that this worry impacted both their attainment and psychological well-being whilst studying abroad.

Separation from the community. As mentioned earlier, Van Gennep (1960) calls the process of detaching from former communities and identities the separation phase. This phase involves a process of negotiation between the student and their families, communities and employers, such as seeking permission to leave and obtaining financial assistance for the venture (Tinto, 1987). Interestingly, far from being honored residents with grand ambitions to study abroad and represent their communities, most of the students in our study made the decision to depart without telling their relatives and extended families. For many, this was due to the ambivalence and anxieties that their communities felt for their ambitions:

I didn't tell the extended family despite living in a close community. If I had told them, they would have said, 'Why do you want to go there? Just get a job!' [Student 34, Nigeria]

Some of my colleagues at work were jealous when I accidentally told them that I was planning to apply for a place in a UK University.

[Student 19, Ghana]

I was scared of telling people that I was leaving because some people in my village practice witchcraft and it is very easy to bewitch people.

[Student 21, South Africa]

Another common theme in the narratives was the need to seek permission from family or the community to leave and go abroad, and 
this was another factor for the students to consider when deciding whether to tell people of their departure.

I had to make up my mind either to stay with my own people or go to pursue my studies overseas. It was a hard decision and I did not fancy telling the wider community in case they said no. [Student 20, Ghana]

In the individualistic West, broadening the mind through travel and study is considered to be a suitable pursuit for young people. However, Triandis and Suh (2002) point out that collectivist cultures, such as many African societies, correlate "negatively with education and exposure to diverse persons" (p.139), possibly because of the disruptive influence that they may bring to the integrity of the community. As such, the group goal of maintaining the community takes precedence over any one individual's desires to study abroad. As one student explains:

It is not common practice in my tribe to let the young people go to places far from their homes. The elders have the right to either say, 'Yes, go', or 'Stay here until you are old enough to look after yourself'. [Student 40, Kenya]

In some communities, the process of seeking permission was formalized by incorporating ritual blessing ceremonies, which held great significance for the students that undertook them:

Before my parents said, 'Yes, you can go and study in the UK', they sent me to my grandparents for our tribal rituals where they poured the herbs and asked the spirits if they would let me leave the family home for a specified period of time. With my grandparents' and ancestral blessings I was allowed to leave the home. [Student 33, Nigeria]

These ceremonies echo the rites of passage that marked key life events in tribal societies, and which Van Gennep, (1960) used as a basis for the stages of adjusting to a new culture. Mensah (1993, p.62) defines rites of passage as: 
Those structures, rituals, and ceremonies by which age-class members or individuals in a group successfully come to know who they are and what they are about, the purpose and meaning for their existence, as they proceed from one clearly defined state of existence to the next state of passage in their lives.

Interestingly, these traditional rituals were in some cases undertaken by families who were also practicing Christians. As one student describes, traditional practices of sacrifice and respecting ancestors are not necessarily considered as being in opposition to their Christian beliefs:

Although we the Africans practice Christianity, our traditional beliefs and witchcraft are still considered part and parcel of our everyday life. We still offer sacrifices in form of animals and chickens to our ancestors. [Student 44, Zimbabwe]

The students in our study clearly felt that traditional ritual events were an important part of their preparations to leave, and served to not only mark the event and signal the giving of permission to leave, but also to set them up for success in the new chapter in their lives: "I am pleased that the grandparents blessed me before I came otherwise I would have had misfortune" [Student 30, Nigeria]. The students for whom departure was sanctioned by their communities, felt clear benefits in terms of how they were adjusting to their new life. According to Bridges (2003), failing to make the appropriate preparations for separation can cause major difficulties for the individual in their transition to a new situation. For many of the students in our study, the complexity and unpredictability of the application process meant that they did not have enough time to prepare themselves or their friends and families for their departure:

I could not tell anyone because I was not sure whether I was coming or not to the UK.

[Student 19, Ghana] 
Only Mum and Dad knew I was going until I got a visa, so I told my closest friends a week before I left. [Student 34, Nigeria]

It is also apparent that the financial demands of the whole endeavor had a direct impact on the way that the separation phase was conducted, as there was no money left for farewell parties or sendoffs. As one student describes, a lack of money meant that her family could not accompany her to the airport:

The most painful experience was the time I left home for the first time accompanied by no family member to the airport. I knew my parents could not afford to pay for both mine and their transport. At the time I did not mind at all but now I feel so ashamed and angry to say the least, that neither my mother nor father dropped me off at the airport.

[Student 11, Sudan]

Despite Lee and Opio's (2011) assertion that Black-African students have few problems with separation from their own environment, it is clear in our sample that separation was in fact a significant and often painful event. A number of the students cried in their interviews when describing leaving their families and many said they had not told their tutors about this sadness, even though it clearly impacted on their academic and social well-being at university. A number of authors have noted that Black-African students tend to "suffer in silence" (Irungu 2013, p.173) and do not value university counselling services as a valid way to deal with their feelings of homesickness and loss (Hyams-Ssekasi et al. 2014, Lee and Opio, 2011; Warren and Constantine, 2007).

\section{DISCUSSION AND CONCLUSIONS}

The picture that emerges from this study of the preparations of BlackAfrican students to leave their home countries reveals a number of stark differences from the norms in the West. Whilst some of these might have been anticipated, the extent of the issues and their impact 
on our students is something that has not previously been acknowledged. First, there is a clear discrepancy between the expectations of Western bureaucratic societies for documenting identity and financial status and the reality for many of our prospective students in Africa. It is not surprising, therefore, that there are difficulties for universities in accurately ascertaining whether a student can pay their fees when students and their parents do not have their own bank accounts. The assumption that international students are rich, and therefore the exceptions to the norms for developing countries, clearly does not stand up to the evidence presented here. It is this assumption that needs challenging on campuses across the West as it prevents university staff from recognizing the determination and resourcefulness that our students have already shown in arriving here to study.

Second, it is clear that there are complex tensions present in many of the communities that our students come from, which impact on their transition and adjustment processes. The literature on widening participation in higher education has revealed the attitudes and ambivalences among the communities of non-traditional domestic students towards going to university (see Colley et al 2014; Greenbank and Hepworth, 2008; Watts and Bridges, 2006), and it is perhaps not surprising that these also exist for international students. Our study of students from African countries has revealed that community members back home can react with both suspicion and jealousy when they hear the news of their departure. It is also clear that in certain cultures, the decision to study abroad may rest with the community rather than with the individual.

This article has shed light on the experiences of a rarely studied group of international students. It has shown that the experiences of students from Africa as they prepare to leave home differ both from the experiences of other, more commonly studied groups of international students, and to norms and expectations that are common for Western students applying to university, in terms of financial status, documentation and the attitudes of their communities to their departure. As Jones and Killick (2007, p. 110) point out, "responding to the diversity of international students and responding to the diversity of home students are in fact not two agendas but one". We need to go beyond the label of 'international student', with the 
stereotypes that this entails, and start to understand the backgrounds of our students, so that we may cater for their needs more fully.

The study presented here was based on students at a single UK university, who were interviewed early in their studies about their experiences of leaving home and adjusting to studying abroad. In order to explore the impact that their separation and transition experiences had on their subsequent educational journey and outcomes, a longitudinal study following students as they continue their studies, graduate and find employment would be required. In addition, it would be interesting to compare the experiences of students at the institution in this study, with other universities both in the UK and other countries. The most popular destination for African students studying abroad is France, and a growing number of students are choosing to study in South Africa, and so it would be illuminating to compare the experiences of students studying in these countries to those of students studying in the UK (ICEF Monitor, 2012).

Another aspect which may be connected to the process of separation from communities and coping with the transition to studying abroad is the religious life of participants. One prominent theme in our analysis was the rituals involved in giving an individual blessing for their journey. Whilst many of our participants referred to strongly held religious beliefs, they were not directly questioned about the link between their traditional ritual practices and their religion, and it was clear from some of the participants that these were not always considered to be the same thing. Whilst it was outside of the scope for this study, it would be interesting to study the link between religion and adjustment to life abroad, and whether students who practise religion have different adjustment experiences to those who do not. We hope that further work in this area will enable us to increase our understanding of the lives of our international students, and ultimately to design culturally inclusive learning environments for all.

\section{REFERENCES}

Abdullah, D., Ismail, M., Aziz, A., Latiff, A., \& Ibrahim, M. (2014). A "research" into international student-related research: (Re) Visualising our stand? Higher Education, 67, 235-253. 
Altbach, P.G. (2012). Corruption: A Key Challenge to Internationalization. International Higher Education, 69, 2-6.

Andrade, M.S. (2006). International students in English-speaking universities. Journal of Research in International Education, 5(2), 131-154.

Beoku-Betts, J. (2006). African women pursuing graduate studies in the sciences: Racism, gender bias, and third world marginality. In J. M. Bird \& S. R. Bystydzienski (Eds.) Removing barriers: Women in academic science, technology, engineering, and mathematics (pp.142-160). Bloomington: Indiana University Press.

Blake, A. C. (2006). The experiences and adjustment problems of Africans at a historically Black institution. College Student Journal, 40, 808-813.

Boafo-Arthur, S. (2014). Acculturative experiences of Black African international students. International Journal of Advanced Counselling, 36, 115-124.

Braun, V. \& Clarke, V. (2006). Using thematic analysis in psychology. Qualitative Research in Psychology, 3(2), 77101.

Bridges, W. (2003). Managing transitions: Making the most of change (2nd ed.). Cambridge, MA: Da Capo Press.

Bryman, A. (2004). Social research methods (2nd ed.). Oxford, UK: Oxford University Press.

Burton, N., Brundrett, M. \& Jones, M. (2008). Doing your education research project. London, UK: Sage.

Butcher, A. (2002). A report on the demographic, social and economic impact of international students on North Shore City. Albany: School of Social and Cultural Studies, Massey University.

Chou, K.L. (2009). Pre-migration planning and depression among new migrants to Hong

Kong: the moderating role of social support. Journal of Affective Disorders, 114, 85-93.

Colley, H., Chadderton, C. \& Nixon, L. (2014). Collaboration and contestation in further and higher education partnerships in England: a Bourdieusian field analysis. Critical studies in Education, 55(2), 104-121. 
Cotton, D. R. E., George, R., \& Joyner, M. (2010). The Attainment Gap Project: Final Report, Plymouth: Plymouth University, Cottrell, S. (2001). Teaching study skills and supporting learning. Basingstoke, UK: Palgrave.

Department for Business, Innovation and Skills (BIS) (2014).

National Strategy for access and student success in higher education. BIS/14/516. Retrieved from https://www.gov.uk/government/publications/nationalstrategy-for-access-and-student-success

Economist (2012, Apr 20). Banking in the developing world: The poor are different. The Economist. Retrieved from http://www.economist.com/blogs/feastandfamine/2012/04/ban king-developing-world

Fischer, N. (2011). Pre- and post-migration attitudes among Ghanaian international students living in the United States: A study of acculturation and psychological wellbeing. Virginia Commonwealth University Theses and Dissertations, Paper 2551.Retrieved from http://scholarscompass.vcu.edu/etd/2551/ Greenbank, P. \& Hepworth, S. (2008). Improving the career decisionmaking behaviour of working class students. Journal of European Industrial Training, 32(7), 492-509.

Hanassab, S. (2006). Diversity, International Students and perceived discrimination: implications for educators and counselors. Journal of Studies in International Education, 10(2), 157-172.

Harry, B., Sturges, K. M., \& Klingner, J. K. (2005). Mapping the process: An exemplar of process and challenge in grounded theory analysis. Researcher, 34, 3-13.

Higher Education Statistics Agency (HESA). (2010). Students in Higher Education Institutions 2008/9. Retrieved from https://www.hesa.ac.uk/stats

Higher Education Statistics Agency. (2014). Region of domicile of non-UK domicile students. Retrieved from https://www.hesa.ac.uk/stats

Higher Education Statistics Agency. (2015). Free online statistics students \& qualifiers. Retrieved from https://www.hesa.ac.uk/free-statistics

Hockings, C. (2010) Inclusive learning and teaching in higher education: a synthesis of research. Retrieved from 
https://www.heacademy.ac.uk/resources/detail/resources/detail /evidencenet/Inclusive_learning_and_teaching_in_higher_edu cation

Huang, I., Raimo, V., \& Humfrey, C. (2014). Power and control: managing agents for international student recruitment in higher education. Studies in Higher Education, 1-22, doi: 10.1080/03075079.2014.968543

Hulme, M., Thomson, A., Hulme, R., \& Doughty, G. (2014). Trading places: The role of agents in international student recruitment from Africa, Journal of Further and Higher Education, 38(5), 674-689.

Hyams-Ssekasi, D. (2012). The transition of International SubSaharan African students into the UK University system with reference to a University in the North of England (Doctoral thesis). University of Huddersfield. Retrieved from http:// eprints.hud.ac.uk/17493/

Hyams-Ssekasi, D., Mushibwe, C.P. \& Caldwell, E.F. (2014). International Education in the UK: The challenges of the Golden Opportunity for Black-African students. Sage Open, 4(4), 1-13.

Hyland F., Trahar S., Anderson J. \& Dickens, A. (2008). A changing world: the internationalization experiences of staff and students (home and international) in UK Higher Education. Escalate. Retrieved from http://escalate.ac.uk/4967

ICEF Monitor. (2012, April 11). Number of Nigerians studying in UK will nearly double by 2015. Retrieved from http://monitor.icef.com/2012/04/number-of-nigeriansstudying-inuk- will-nearly-double-by-2015/

Irungu, J. (2013). African students in the US higher education system: A window of opportunities and challenges. In H. C. Alberts \& H. D. Hazen (Eds.), International students and scholars in the United States: Coming from Abroad (pp. 163-180). New York, NY: Palgrave MacMillan.

Jones, E., \& Killick, D. (2007). Internationalisation of the curriculum. In E. Jones \& S. Brown (Eds.), Internationalising higher education (pp. 109-119). London, UK: Routledge. 
Lee, J., \& Opio, T. (2011). Coming to America: Challenges and difficulties faced by African student athletes. Sport, Education and Society, 16, 629-644.

Lee, J., \& Rice, C. (2007). Welcome to America? International student perceptions of discrimination. Higher Education, 53, 381-409.

Leney, K. (1999). African students in Europe. Journal of African History, 40, 321-322.

Lewin, T. (2008, May 11). Matching Newcomers to College, While both Pay. The New York Times. Retrieved from http://www.nytimes.com/2008/05/11/education/11agents.html ?pagewanted=all

Lewthwaite, M. (1996). A study of international students' perceptions on cross-cultural adaptation. International Journal for Advancement of Counselling, 19(2), 167-185.

Lipset, A. (2009, May 18). Genuine overseas students 'denied entry to UK" Great suspicion of foreign students by UK Border Agency is risking cashflow for higher education, complain business school leaders. The Guardian. Retrieved from http://www.guardian.co.uk/education/2009/may/18/overseasstudents-denied-entry

Manyika, S. (2001). Negotiating identities: African students in British and American universities. Dissertation Abstracts International, 62(1-A), 97.

Maringe, F., \& Carter, S. (2007). International students' motivations for studying in UK HE: Insights into the choice and decision making of African students. International Journal of Educational Management, 21, 459-475.

Maunder, R.E., Cunliffe, M., Galvin, J., Mjali, S., \& Rogers, J. (2013). Listening to student voices: student researchers exploring undergraduate experiences of university transition Higher Education, 66:139-152.

Mensah, A.J. (1993). Rites of passage and initiation process with Akan Culture. Milwaukee, WI: University of Wisconsin.

Mwara, J. N. (2008). Non-traditional age Black African international students' experiences: Phenomenological heuristic inquiry. Adult Education Research Conference Proceeding. Retrieved from 
http://www.adulterc.org/Proceedings/2008/Proceedings/Mwau ra.pdf

McNeill , P., \& Chapman, S. (2005). Research methods (3rd ed.). London, UK: Routledge.

National Union of Students (NUS) (2014). Widening the safety net: International students in unexpected financial hardship and what can be done. Retrieved from http://www.nusconnect.org.uk/resources/open/international/W idening-the-Safety-Net-Bringing-Financial-Safety-toInternational-Students/

Nortier, F. (1995). A New angle on coping with change: Managing transition. Journal of Management Development, 14(4), 32-46.

Pimpa, N. (2003). The Influence of Peers and Student Recruitment Agencies on Thai Students' Choices of International Education. Journal of Studies in International Education, 7(2), 178-92.

Ryan, L., Leavey, G., Golden, A., Blizard, R., \& King, M. (2006). Depression in Irish migrants living in London: case-control study. British Journal of Psychiatry, 188, 560-566.

Schlossberg, N.K. (1984). Counseling adults in transition: Linking practice with theory. New York: Springer.

Schlossberg, N.K., Waters, E.B., \& Goodman, N,J. (1995). Counseling adults in transition: Linking practice with theory, (2nd Ed.). New York: Springer.

Serra Hagedorn, L., \& L. Yi Zhang. (2011). The Use of Agents in Recruiting Chinese Undergraduates. Journal of Studies in International Education, 15(2), 186-202.

Sharma, A. (1997). Professional as Agent: Knowledge Asymmetry in Agency Exchange. The Academy of Management Review, 22, 758-98.

Sidoryn, T. \& Slade, J. (2008, December 2-5). To transition and beyond! Strategies to assist international students throughout their university. Paper presented at the 19th ISANA International Education Conference, Auckland, NZ. Retrieved from, http://www.proceedings.com.au/isana/2008.html

Sidy, F. (2007). Visa denials for African students. Diverse Issues in Higher Education, 23(24), 8-10. 
te Riele, K. (2004). Transition experiences of marginalised students: biased or useful? Paper Presented at the Australian Association for Research in Education Annual Conference, University of Melbourne.

Tinto, V. (1987). Leaving college. Chicago, IL: University of Chicago Press.

Triandis, H.C. and Suh, E.M. (2002). Cultural Influences On Personality. Annual Review. Psychology, 53, 133-60.

Unicef (2003) Factsheet: Birth Registration. Retrieved from http://www.unicef.org/newsline/2003/03fsbirthregistration.ht $\mathrm{m}$

University of Plymouth (2015) Inclusive Teaching and Learning Research. Retrieved from: https://www.plymouth.ac.uk/youruniversity/teaching-and-learning/inclusivity/inclusivityresearch

Van Gennep, A. (1960). The rites of passage. London, UK. Routledge and Kegan.

Warren, K. A., \& Constantine, M. G. (2007). Counseling African international students. In D. H. Singaravelu \& M. Pope (Eds.), A handbook for counseling international students in the United States (pp. 211-222). Alexandria, VA: American Counseling Association.

Watts, M., \& Bridges, D. (2006). The value of non-participation in higher education. Journal of Education Policy, 21(3), 267290.

Weise, K. (2012, April 25). Why half the world doesn't have bank accounts. Bloomberg Business. Retrieved from http://www.bloomberg.com/bw/articles/2012-04-25/why-halfthe-world-doesnt-have-bank-accounts

Yorke, M. (1999). Leaving early: undergraduate non-completion in higher education. London, UK: Falmer.

Zhoua, Y., Jindal-Snapea, D., Toppinga, K., \& Todmana, J. (2008). Theoretical models of culture shock and adaptation in international students in higher education. Studies in Higher Education, 33(1), 63-75. 
ELIZABETH CALDWELL, Ph.D., is an Academic Skills Tutor at the University of Huddersfield, UK. She received her $\mathrm{PhD}$ from University College London and her current research centers around the theory and practice of Higher Education, including the experiences of international students studying abroad. Email: E.Caldwell@hud.ac.uk

DENIS HYAMS-SSEKASI Ed. D., is a Lecturer in Business Management at the University of Bolton, UK. His research interests include the transitional experiences of international students in Higher Education, as well as intercultural communication and social impacts. Email: D.Hyams-Ssekasi@bolton.ac.uk

Manuscript submitted: July 16, 2015

Manuscript Revised: October 12, 2015 Accepted for publication: January 9, 2016 